\title{
Approach to Treat Insomnia in Substance Use Disorder Population
}

\author{
Usman Riaz ${ }^{1},{ }^{*}$ and Syed Ali Riaz ${ }^{2}$ \\ ${ }^{1}$ Division of Substance Abuse, Department of Psychiatry, Montefiore Medical \\ Center/ Albert Einstein College of Medicine, Bronx, NY, USA
}

${ }^{2}$ Department of Pulmonology/Critical Care and Sleep Medicine, Virtua Health, New Jersey, USA

\begin{abstract}
The insomnia is a well-known presenting complaint among substance use disorder patients, as untreated insomnia can lead to major consequences, including is a risk factor for relapse on alcohol/ drugs. Therefore, treatment of this comorbid disorder is indeed important and should be a part of treatment plan while treating an addiction population. The insomnia can be a presenting compliant during acute intoxication and withdrawals period and could persist on chronic basis, which needs to be addressed in a timely manner to avoid adverse consequences. During acute intoxication and withdrawals phase of treatment, main recommendation should be to abstain from the substances that induce it. The medications for insomnia be prescribed only on as needed basis in acute phase of intoxication and withdrawals. If insomnia complaints persist after abstinence from alcohol/drugs, the initial approach should be cognitive and behavioral therapies, which has been proven to address insomnia on long term basis in a general population. The same approach should be applied to substance use disorder patients, though there is a limited data in regards to those therapeutic approaches in substance abuse population. As per medication management few medications like Benzo-receptor agonist hypnotics (Benzodiazepines and Nonbenzodiazepines) should be strongly discouraged secondary to its dependency/tolerance and mortality related issues in substance abuse population. The other FDA approved medications, such as (Ramelteon, Doxepin, Suvorexant) can be preferred over Benzoreceptor agonist medications. In clinical practice the off-label use of Trazodone, Quetiapine, Mirtazapine, Hydroxyzine and Gabapentin
\end{abstract}

*Corresponding authors: Usman Riaz, Division of Substance Abuse, Department of Psychiatry, Montefiore Medical Center/Albert Einstein College of Medicine, Bronx NY, USA, Tel: +1 7188293440; E-mail: usmansyedriaz@gmail.com

Citation: Riaz U, Riaz SA (2020) Approach to Treat Insomnia in Substance Use Disorder Population. J Addict Addictv Disord 7: 57.

Received: October 08, 2020; Accepted: October 21, 2020; Published: October 30,2020

Copyright: (c) 2020 Riaz U, et al. This is an open-access article distributed under the terms of the Creative Commons Attribution License, which permits unrestricted use, distribution, and reproduction in any medium, provided the original author and source are credited. is common to treat insomnia in substance users, which at times justify its use, particularly with comorbid psychiatric issues.

Keywords: Cognitive behavioral therapy for insomnia; Insomnia; Substance use disorder population

\begin{abstract}
Abbreviations
CBT-I: Cognitive behavioral therapy for insomnia;

BBT: Brief behavioral therapy;

ICSD3: International classification of sleep disorders; DSM5: Diagnostic manual of psychiatric disorders 5; qhs: nightly; Bz: Benzodiazepine.
\end{abstract}

\section{Introduction}

Chronic insomnia disorder patient reports or patients parent or caregiver observes $>1$ of the following difficulty initiating sleep, maintain sleep, waking up earlier than desired, resistance to go to bed on appropriate schedule, difficulty sleeping without parent or caregiver intervention and patient reports or parent or caregiver observed one or more of following related to nighttime sleep difficulty (Fatigue/malaise, attention concentration or memory impairment, impaired social, family, occupational or academic performance, mood disturbance/irritability, day time sleepiness, behavioral problems such as, hyperactivity, impulsivity/aggression, reduced motivation/energy/ initiative, prone for errors/ accident, concerns about or dissatisfaction with sleep) [1]. The reported sleep/wake complaints can't be purely explained by inadequate opportunity or inadequate circumstances and sleep disturbance and associated sleep daytime symptoms occur at least three time per week for three months and is not better explained by another sleep disorder. Insomnia leads to impair cognitive functioning, negative quality of life measures, increase incidence of bodily pain, poor general health, increase future risk of psychiatric disorders [2], decrease job performance, increase absenteeism, increase risk of accidents, increased health care cons [3].

According to ICSD-3 Substances that induced sleep disorders are Alcohol, Opioids, Cannabis, Sedatives, Hypnotics or Anxiolytics, Cocaine, Stimulants, Hallucinogens, Nicotine and Inhalants. As per DSM 5 all above-mentioned substances induce sleep wake cycle disorder.

The mood disorders, anxiety disorders, psychotic disorders, substance use disorders are comorbid with insomnia, The prevalence of drug abuse in insomnia subjects is $4.2 \%$ according to one cross sectional study and persistent insomnia predicts future alcohol abuse at 1 year follow up according to that study [4]. Compare to patients without insomnia, patients with insomnia were more likely to report frequent alcohol use for sleep (55\% vs. $28 \%$ ) and relapse to any use of alcohol was much higher in baseline insomnia vs. without baseline 
insomnia subjects $60 \%$ vs. $30 \%$ [5]. University of California, Los Angeles gambling sleep study results showed gamblers were 3.5 times more likely to experience a sleep problem compared to individuals who didn't have gambling problem [6].

Among insomnia subjects there are areas in brain that don't deactivate from waking to sleep, like ascending reticular activating system, Hypothalamus, Mesial temporal cortex, Thalamus, Insular cortex [7]. Insomnia is a disorder of hyper arousal, hypothalamus pituitary axis activation, cognitive arousal, sympathetic activation and mood disturbance. There is significant 24-hour increase in cortisol [8], increased metabolic rate, increased body temperature, increased heart-rate, increased catecholamine, increased EEG high frequency/ low frequency ratio [9] and hyper metabolism in insomnia patients [7].

\section{Non-pharmacological approach to treat insomnia}

Psychological and behavioral interventions are effective and recommended in the treatment of chronic insomnia. These treatments are effective for adults of all ages. The treatment should be utilized as an initial intervention when appropriate and conditions permit.

Behavioral and cognitive behavioral therapies demonstrated efficacy in moderate to high quality randomized controlled trials. CBT is as effective as prescription medication for short-term treatment of insomnia and beneficial effects of CBT in contrast to those produced by medications, may last well beyond the termination of active treatment.

\section{CBT-I}

Initial approaches of CBT-I should include at least one behavioral treatment such as stimulus control therapy and or sleep restriction, with or with relaxation [10]. CBT-I is better than pharmacotherapy for insomnia in older subjects at 24 months $\mathrm{f} / \mathrm{u}$ [11]. Also limited data support CBT-I approach/success in substance users $[12,13]$.

Components of CBT-I: Typical CBT-I treatment plan consists of 4-5 session followed by booster session.

Sleep restriction: Particularly effective for patients spending too much time on beds, it improves sleep continuity by limiting time spent in bed to match reported time sleep. Increases sleep drive via sleep deprivation, effective for both sleep onset and maintenance problems. It's all about sleep efficiency. Normal sleep efficiency is $90-95 \%$ in adult population; No one ever sleeps $100 \%$ of bedtime. Goal is $85 \%$. Calculate sleep efficiency from sleep diary. Time asleep/time in bed. Time asleep $=$ Time in bed-(time to fall sleep + time awake at night). Determine patients current, subjective totals sleep time using sleep diaries and history, and establish a fixed awake up time. Work backwards from the desired wake time; determine patient's bedtime. No sleep is permitted outside of this window. Sleep efficiency is monitored and bedtime is adjusted accordingly [14].

Sleep diary: is the thermometer of CBT-I, introduced at the end of first assessment visit and completed throughout treatment, reviewed at beginning of each session, essential for successful treatment.

Stimulus control: Considered one of the most effective behavioral treatments, useful for both sleep onset and maintenance problems. It's based on behavioral principle of classical conditioning. Insomnia leads to stress, anxiety, wakefulness, this takes place in bed, and the bed becomes associated with stress, anxiety and wakefulness [15] The treatment involves changing the association: worry/wakefulness, waiting, a bed should be a cue for sleep by not sleeping in bed if not asleep. Over one or more nights, sleep drive increases and sleep onset occur more quickly. Over multiple trails, the bed is again associated with rapid sleep onset. The typical instructions are, fixed morning rise times, 7 days a week, regardless of how much you sleep during the night, The bed is only for sleep and sex, no couch napping, only on bed, go to bed when sleepy, leave the bed room if awake for $>20$ minutes, no clock watching, return to bed only when sleepy, don't nap in the day. What to do if awake $>20$ minutes in bed? Leave the bedroom and partake in quiet and sedentary activities, don't do something where you lose track of time, don't get too comfortable, don't give yourself too much light, go to bed when you cant stay up any longer, don't cook full meal for next day.

Sleep hygiene: Avoid caffeine, nicotine, alcohol, eat a light time bedtime snack, Sleep in quiet dark room, comfortable temperature, good matters, Limit/avoid napping, exercise in afternoon/early evening. Eat a light bedtime snack to avoid awakening from drop in blood sugar at night [16].

Worry Time: During the day, schedule a worry time; find a specific place to worry. At night remind yourself you will have time to worry about these things tomorrow (during worry time). Once solutions have been generated, the worry will come up less often when you are in bed at night.

Cognitive therapy: Challenge dysfunctional beliefs about sleep:"I must sleep 8 hours", correct unrealistic expectations "I should never wake up at night, Reconsider insomnia consequences "I can't function without 8 hours of sleep ". These cognitive dysfunctional beliefs require cognitive restructuring to address those automatic negative beliefs regarding sleep [17].

Internet assisted CBTI: Data suggested that these are affective, particularly when therapists are not available [18].

Relapse prevention: Relapse is not one bad night, a return of insomnia may be a sign of other psychological distress, insomnia may be a prodromal symptom of depression, alcohol abuse relapse, if insomnia returns restrict and control and aim for 5/7 good nights,

\section{Brief behavioral treatment of insomnia BBTI}

It is a further modification of CBT-I and includes only four basic steps.

1. Reduce total time in bed;

2. Don't go to bed unless you are sleepy;

3. Don't stay in bed unless you are a sleep ;

4. Get up at the same time every day of the week, no matter how much you slept the night before [19].

\section{EBB (comfort band for insomnia)}

The first FDA-approved, non-pharmacologic treatment for insomnia, it uses a cooling headband that is supposed to help fall asleep and reach deeper stages of restorative sleep. Several clinical trials support the effectiveness of Ebb. Even though it's just a headband, it requires a prescription to purchase. Ebb is the first and only drugfree solution that uses targeted cooling to reduce metabolic activity in the frontal cortex of the brain, helping to calm mind and body. 
There is a reduced brain activity and racing mind with Ebb to help reach deeper, more restorative sleep faster. The frontal cortex works overtime in individuals with sleeplessness, creating racing thoughts and making it difficult for the brain to drift naturally into sleep and stay asleep across the night. This racing mind effect is demonstrated via increased metabolic activity in the frontal cortex of the brain [20]. By applying precise, constant cooling to the forehead of individuals with sleeplessness led to significant reductions in metabolic activity in the frontal cortex of the brain. These reductions in activity allowed participants to fall asleep faster and achieve better sleep across the night [21].

\section{Pharmacological treatment options to treat insomnia}

FDA Approved medications: The FDA approved medications are: Benzodiazepine receptor agonist (Benzodiazepines and Nonbenzodiazepine hypnotics), Selective melatonin receptor agonist (Ramelteon 8mg), selective histamine receptor antagonist (Low dose Doxepin 3mg-6mg), and dual orexin/hypocretin receptor antagonist (Suvorexant 10mg-20mg).

A lot of data is not in favor of Benzodiazepines receptor agonist medications secondary to safety risk, particularly in substance abuse population. In a large cohort of patients attending United Kingdom prime care, anxiolytics and hypnotics drugs were associated with significant mortality over seven years period, after adjusting for a arrange of potential confounders. The dose response association with mortality found for all the these classes of study drugs. (Benzodiazepines, Z drugs (Zaleplon, Zolpidem, Zopiclone) [22]. The fatal toxicity of Zopiclone was not significantly different from that of Benzodiazepines as a group when adjusted for usage [23]. Benzodiazepines receptor agonist binds with $\mathrm{Bz} 1, \mathrm{Bz} 2$ and $\mathrm{Bz} 3$ receptors (Non selective). Bz1: hypnotic and amnestic Bz2 and Bz3 antiseizure, and muscle relaxing. Non-benzodiazepine receptor agonists bind with Bz1 GABA receptor only (selective) and act as an allosteric modulator.

\section{Non-FDA approved medications}

The non-FDA approved medications for insomnia are: Diphenhydramine (25-100mg qhs), Gabapentin (100-900mg), Hydroxyzine (25-100mg), Melatonin (1-3mg qhs), Mirtazapine (7.5mg-15mg), Trazodone (25-200mg qhs). In clinical practice use of psychotropic for insomnia can be justified, particularly if there is comorbid psychiatric issue, since untreated insomnia can lead to most of psychiatric problems.

\section{Conclusion}

The treatment of insomnia should be a part of recovery plan in substance use population; otherwise chance of relapse is higher. Though cognitive/ behavioral therapies are first line recommendation to treat chronic insomnia, its utilization in substance use population as a first line treatment option could be difficult at times secondary to nature of addiction disease. Benzodiazepines receptor agonist (benzodiazepine and non-benzodiazepine hypnotics) should be avoided if possible due to risk of dependency/tolerance/mortality associated with it. The cognitive and behavioral therapy as an initial treatment plan, with or without medication is still a preferred treatment approach. The treatment approaches like use of EBB is available in market and seems to be a reasonable approach to treat insomnia in substance use disorder population as well. Other FDA approved medications like Remelton, Doxepin, Suvorexant should be preferred over Benzodiazepines receptor agonist hypnotics in substance users. The non-FDA approved medications can be prescribed particularly if there are comorbid psychiatric issues.

\section{Acknowledgement}

None.

\section{Role of the Funding Source}

Author's states that this study was not financed.

\section{Contributors}

Both authors contributed equally to this manuscript.

\section{Conflict of Interest}

Authors have no conflict of interest.

\section{References}

1. Zammit GK, Weiner J, Damato N, Sillup GP, McMillan CA (1999) Quality of life in people with insomnia. Sleep 2: 379-385.

2. Breslau N, Roth T, Rosenthal L, Andreski P (1996) Sleep disturbance and psychiatric disorders: A longitudinal epidemiological study of young adults. Biol Psychiatry 39: 411-418.

3. American academy of sleep medicine (2014) International classification of sleep disorders. Third edition. Darien, USA.

4. Ford DE, Kamerow DB (1989) Epidemiologic study of sleep disturbances and psychiatric disorders. An opportunity for prevention? JAMA 262: 1479-1484.

5. Brower KJ, Aldrich MS, Robinson EA, Zucker RA, Greden JF (2011) Insomnia, self-medication, and relapse to alcoholism. Am J Psychiatry 158: 399-404.

6. Parhami I, Siani A, Rosenthal RJ, Fong TW (2013) Pathological gambling, problem gambling and sleep complaints: An analysis of the National Comorbidity Survey: Replication (NCS-R). J Gambl Stud 29: 241-253.

7. Nofzinger EA, Buysse DJ, Germain A, Price JC, Miewald JM, et al. (2004) Functional neuroimaging evidence for hyperarousla in insomnia. Am J Pyschiatry 161: 2126-2129.

8. Vgontzas AN, Bixler EO, Lin HM, Prolo P, Mastorakos G, et al. (2001) Chronic insomnia is associated with nyctohemeral activation of the hypothalamic-pituitary-adrenal axis: Clinical implications. J Clin Endocrinol Metab 86: 3787-3794.

9. Bonnet MH, Arnad D (1998) Heart rate variability in insomniacs and matched normal sleepers. Psychosom Med 60: 610-615.

10. Schutte-Rodin S, Broch L, Buysse D, Dorsey C, Sateia M (2008) Clinical guideline for the evaluation and management of chronic insomnia in adults. J Clin Sleep Med 4: 487-504.

11. Morin CM, Coechhi C, Stone J, Sood R, Brink D (1999) Behavioral and pharmacological therapies for late-life insomnia : a randomized controlled trial. JAMA 281: 991-999.

12. Arnedt JT, Conroy DA, Armitage R (2011) Cognitive behavioral therapy for insomnia in alcohol dependent patients: A randomized controlled pilot trial. Behav Res Ther 49: 227-233.

13. Currie SR, Clarke S, Hodgins DC, El-Gluebaly N (2004) Randomized controlled trial of brief cognitive behavioral interventions for insomnia in recovering alcoholics. Addiction 99: 1121-1132. 
14. Spielman AJ, Saskin P, Thorpy MJ (1987) Treatment of chronic insomnia by restriction of time in bed. Sleep 10: 45-56.

15. Chesson A1, Anderson WM, Littner M (1999) AASM standards of practice committee. Sleep 22: 1-6.

16. Stepanski EJ, Wyatt JK (2003) Use of sleep hygiene in the treatment of insomnia. Sleep Med Rev 7: 215-225.

17. Morin CM (2004) Cognitive behavioral approaches to the treatment of insomnia. J Clin Psychiatry 65: 33-40.

18. Ritterband LM, Thorndike FP, Gonder-Frederick LA, Magee JC, Bailey ET, et al. (2009) Efficacy of an Internet-based behavioral intervention for adults with insomnia. Arch Gen Psychiatry 66: 692-698.

19. Buysse DJ, Germain A, Moul DE, Franzen PL, Brar LK, et al. (2011) Efficacy of brief behavioral treatment of chronic insomnia in older adults. Arch Intern Med 171: 887-895.
20. Nofzinger E (2006) Evidence of racing thoughts in adults with sleeplessness. Journal of Clinical Sleep Medicine 2: 316-322.

21. Nofzinger E (2009) Precise, constant therapeutic cooling of the forehead reduces racing thoughts in adults with sleeplessness. Sleep Journal.

22. Weich S, Pearce HL, Croft P, Singh S, Crome I (1996) Effect of anxiolytic and hypnotic drug prescriptions on mortality hazards: Retrospective cohort study. BMJ 19: 348.

23. Reith DM, Fountain J, McDowell R, Tilyard M (2003) Comparison of the fatal toxicity index of zopiclone with benzodiazepines. J Toxicol Clin Toxicol 41: 975-980. 


\section{If}

Advances In Industrial Biotechnology | ISSN: 2639-5665

Advances In Microbiology Research | ISSN: 2689-694X

Archives Of Surgery And Surgical Education | ISSN: 2689-3126

Archives Of Urology

Archives Of Zoological Studies | ISSN: 2640-7779

Current Trends Medical And Biological Engineering

International Journal Of Case Reports And Therapeutic Studies | ISSN: 2689-310X

Journal Of Addiction \& Addictive Disorders | ISSN: 2578-7276

Journal Of Agronomy \& Agricultural Science | ISSN: 2689-8292

Journal Of AIDS Clinical Research \& STDs | ISSN: 2572-7370

Journal Of Alcoholism Drug Abuse \& Substance Dependence | ISSN: 2572-9594

Journal Of Allergy Disorders \& Therapy | ISSN: 2470-749X

Journal Of Alternative Complementary \& Integrative Medicine | ISSN: 2470-7562

Journal Of Alzheimers \& Neurodegenerative Diseases | ISSN: 2572-9608

Journal Of Anesthesia \& Clinical Care | ISSN: 2378-8879

Journal Of Angiology \& Vascular Surgery | ISSN: 2572-7397

Journal Of Animal Research \& Veterinary Science | ISSN: 2639-3751

Journal Of Aquaculture \& Fisheries | ISSN: 2576-5523

Journal Of Atmospheric \& Earth Sciences | ISSN: 2689-8780

Journal Of Biotech Research \& Biochemistry

Journal Of Brain \& Neuroscience Research

Journal Of Cancer Biology \& Treatment | ISSN: 2470-7546

Journal Of Cardiology Study \& Research | ISSN: 2640-768X

Journal Of Cell Biology \& Cell Metabolism | ISSN: 2381-1943

Journal Of Clinical Dermatology \& Therapy | ISSN: 2378-8771

Journal Of Clinical Immunology \& Immunotherapy | ISSN: 2378-8844

Journal Of Clinical Studies \& Medical Case Reports | ISSN: 2378-8801

Journal Of Community Medicine \& Public Health Care | ISSN: 2381-1978

Journal Of Cytology \& Tissue Biology | ISSN: 2378-9107

Journal Of Dairy Research \& Technology | ISSN: 2688-9315

Journal Of Dentistry Oral Health \& Cosmesis | ISSN: 2473-6783

Journal Of Diabetes \& Metabolic Disorders | ISSN: 2381-201X

Journal Of Emergency Medicine Trauma \& Surgical Care | ISSN: 2378-8798

Journal Of Environmental Science Current Research | ISSN: 2643-5020

Journal Of Food Science \& Nutrition | ISSN: 2470-1076

Journal Of Forensic Legal \& Investigative Sciences | ISSN: 2473-733X

Journal Of Gastroenterology \& Hepatology Research | ISSN: 2574-2566
Journal Of Genetics \& Genomic Sciences | ISSN: 2574-2485

Journal Of Gerontology \& Geriatric Medicine | ISSN: 2381-8662

Journal Of Hematology Blood Transfusion \& Disorders | ISSN: 2572-2999

Journal Of Hospice \& Palliative Medical Care

Journal Of Human Endocrinology | ISSN: 2572-9640

Journal Of Infectious \& Non Infectious Diseases | ISSN: 2381-8654

Journal Of Internal Medicine \& Primary Healthcare | ISSN: 2574-2493

Journal Of Light \& Laser Current Trends

Journal Of Medicine Study \& Research | ISSN: 2639-5657

Journal Of Modern Chemical Sciences

Journal Of Nanotechnology Nanomedicine \& Nanobiotechnology | ISSN: 2381-2044

Journal Of Neonatology \& Clinical Pediatrics | ISSN: 2378-878X

Journal Of Nephrology \& Renal Therapy | ISSN: 2473-7313

Journal Of Non Invasive Vascular Investigation | ISSN: 2572-7400

Journal Of Nuclear Medicine Radiology \& Radiation Therapy | ISSN: 2572-7419

Journal Of Obesity \& Weight Loss | ISSN: 2473-7372

Journal Of Ophthalmology \& Clinical Research | ISSN: 2378-8887

Journal Of Orthopedic Research \& Physiotherapy | ISSN: 2381-2052

Journal Of Otolaryngology Head \& Neck Surgery | ISSN: 2573-010X

Journal Of Pathology Clinical \& Medical Research

Journal Of Pharmacology Pharmaceutics \& Pharmacovigilance | ISSN: 2639-5649

Journal Of Physical Medicine Rehabilitation \& Disabilities | ISSN: 2381-8670

Journal Of Plant Science Current Research | ISSN: 2639-3743

Journal Of Practical \& Professional Nursing | ISSN: 2639-5681

Journal Of Protein Research \& Bioinformatics

Journal Of Psychiatry Depression \& Anxiety | ISSN: 2573-0150

Journal Of Pulmonary Medicine \& Respiratory Research | ISSN: 2573-0177

Journal Of Reproductive Medicine Gynaecology \& Obstetrics | ISSN: 2574-2574

Journal Of Stem Cells Research Development \& Therapy | ISSN: 2381-2060

Journal Of Surgery Current Trends \& Innovations | ISSN: 2578-7284

Journal Of Toxicology Current Research | ISSN: 2639-3735

Journal Of Translational Science And Research

Journal Of Vaccines Research \& Vaccination | ISSN: 2573-0193

Journal Of Virology \& Antivirals

Sports Medicine And Injury Care Journal | ISSN: 2689-8829

Trends In Anatomy \& Physiology | ISSN: 2640-7752

Submit Your Manuscript: http://www.heraldopenaccess.us/Online-Submission.php 